\title{
Evaluation of the Ecological Flow Considering Hydrological Alterations in the Baihe River, Northern China
}

\author{
Guangling Hao, Xuan Wang, Peiyu Liang, and Guannan Cui
}

\begin{abstract}
The Mann-Kendall test was applied to analyzing the shift points and defining the hydrologic series of the river stream flow from 1963 to 2011 . The Tennant method was subsequently used to evaluate the ecological flow and the monthly guaranteed frequency method was applied to calculating the monthly ecological water requirements in two different hydrologic series. The results were as follows. 1) The years during 1963 - 1985 and the years during 1986 - 2011 were distinguished as two hydrologic series. 2) The ecological flow was generally in better condition in other season than that in spawning season. During the spawning season, $87.0 \%$ of stream flow was not at the appropriate level before 1985 and $72.4 \%$ after 1986, which indicated a worse condition for the reproduction and breeding of aquatic organisms. 3) The monthly ecological water requirement varied and showed a decreased trend, consistent with the stream flow regime. This research helps to deepen understanding of the evaluation of the ecological flow and to provide a basis for decision making and reservoir regulations with hydrological alterations.
\end{abstract}

Index Terms-Hydrologic alterations, ecological flow, Mann-Kendall test, tennant method, monthly guaranteed frequency method.

\section{INTRODUCTION}

With the global environmental changes and continuing exploitation of water resources, river stream flow decrease even river blanking appeared all over the world [1]. Such serious environmental problems will not only lead to water quality deterioration, threaten the river livings but also hinder the development of social economy. Rivers are fundamental aquatic ecosystems, which rely heavily on flux to maintain primary conditions [2]. Evaluation of the ecological instream flow was the fundamental for protection of the river ecosystem, which will help to understand the condition of the river stream flow and to maintain system integrity. Many methods, including the historic flow regime method, habitat method and hydraulic method, were introduced to calculate ecological flow [3]. As one of the historic flow regime methods, the Tennant method was developed to determine the appropriate discharge for saving fish-passing in the USA [4].

Manuscript received June 14, 2015; revised September 18, 2015. This research was supported by the Fund for Innovative Research Group of the National Natural Science Foundation of China

Guangling Hao, Xuan Wang, and Guannan Cui are with the School of Environment, Beijing Normal University, Beijing 100875, China (e-mail: HGL370@163.com,wangx@bnu.edu.cn, dandancuicui@gmail.com).

Peiyu Liang was in Beijing Normal University. He is now with the Zhejiang Institute of Hydraulics and Estuary, Hangzhou 310020, China (e-mail: 758856495@qq.com).
It relied solely on the recorded or estimated flow regime of the river, so it needed less data and was widely used to recommend the ecological flow, especially when water quality or temperature of the water bodies were not inadequate [5]. In addition, in an attempt to give a base for water resource planning and reservoir regulations, the calculation of the water ecological requirement was needed. Considering the present research in China, the hydrology and hydraulics methods are two suitable methods for China's river flow research [6]. Among these methods, the monthly guaranteed frequency (MGF) method is one of the hydrology method applied to calculate the water ecological requirement suitable for the river regime of northern China.

However, the earlier research on evaluation of the ecological in stream flow and calculations of the water ecological requirements were with little consideration of the stream flow variations. In order to guarantee the health of river ecosystem, the ecological flow would be better evaluated with consideration of hydrological alterations. Much research has been performed to analyze hydrological alterations of the river stream flow. Chen et al. [7] analyzed the long monthly stream flow series of the Pearl River by using the scanning F-test. The results demonstrated that the annual minimum stream flow of the Pearl River tended to increase, and the variations of the stream flow were influenced by both climate changes and human activities. Bao et al. [8] applied the Mann-Kendall (MK) test to analyze the trends and the corresponding shift points of stream flow of the Haihe River Basin, which showed that the shift point of annual stream flow in the Chaohe River was the year of 1999 and that in the Baihe River was the year of 1980. Birsan et al. [9] analyzed the trends of mean daily stream flow of 44 rivers in Romania with the MK test. The main identified stream flow trends increased in winter and autumn since 1961, and decreased in summer since 1975. Actually, as a conventional non-parametric test method recommended by the World Meteorological Organization, the MK test, due to its clear advantage over other methods in terms of time and precision, has been widely used to identify hydrological alterations in time series [10].

In this paper, comprehensive analysis methods were conducted in this paper: 1) the MK test was applied to detecting shift points and distinguishing the different hydrological series of the river stream flow; 2) the assurance of the eco-environmental flow for the Baihe river were evaluated by the Tennant method; 3) the MGF method adopted to calculate water ecological requirements in each month with considering the streamflow variations. Thus, it 
will provide a valuable basis for the rational relocation and utilization of water resources and ecosystem protection of the rivers under hydrological alterations.

\section{MATERIALS AND METHODS}

\section{A. Study Area and Data Source}

The Baihe River is situated in the upstream of the Miyun Reservoir, which is an important surface water source of drinking water for Beijing City (Fig. 1). The Miyun Reservoir is located to the northeast of Beijing City, the capital of China with a population of more than 20 million. The Baihe River located between longitude $115.25-117.00^{\circ} \mathrm{E}$ and latitude $40.25 \mathrm{~N}-41.30^{\circ} \mathrm{N}$. The stream flows of the Baihe River fluctuated and generally decreased from 1963 to 2011 (Fig. 2). The annual average stream flow of the Baihe River decreased by an average of $0.37 \mathrm{~m}^{3} / \mathrm{s}$ every year. The linear fitting results of annual stream flow exhibited intuitively downward trend during 1963 - 2011 (Fig. 2). The long-term stream flow data in the research were obtained from the "Hydrological Year Book" provided by the Miyun Reservoir Administration Office. The time series of stream flow data were recorded at Zhangjiafen covering the period from January, 1963 to December, 2011. According to the local climate characteristics, April - September and October - next March was discriminated from spawning season and other season respectively.

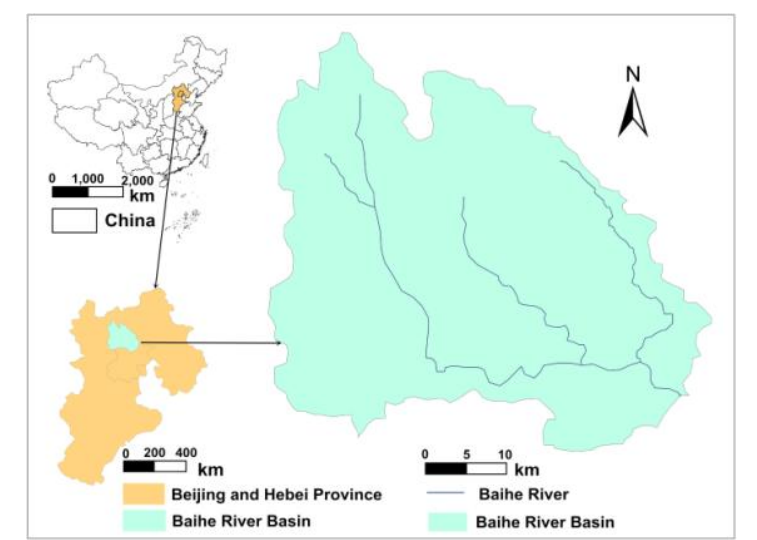

Fig. 1. Location of the study area of the Baihe River, Northern China.

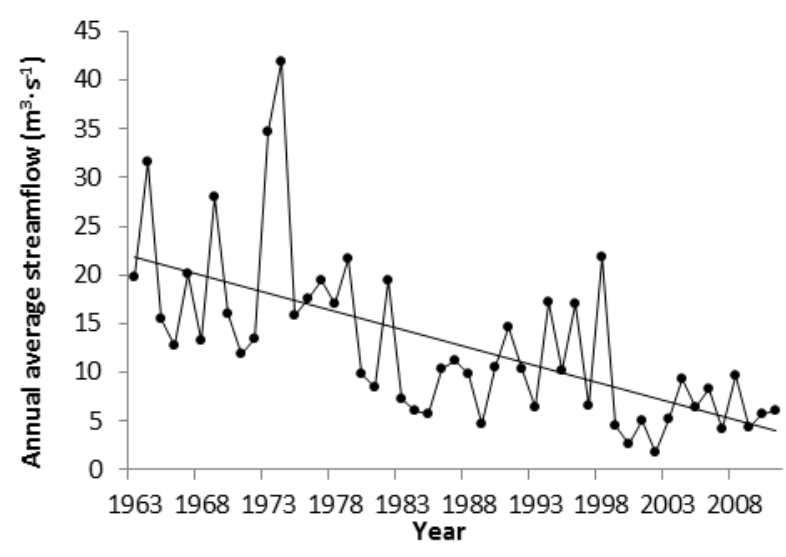

Fig. 2. Variations of annual average stream flow of the Baihe River.

\section{B. Method}

1) The MK test
The MK test was applied to analyzing the aberrance of stream flow and distinguishing the different hydraulic series of the Baihe River. The MK test is a non-parametric, rank-based method for detecting aberrance in a time-series (Marengo et al. 1998). For a series $x_{1}, x_{2}, x_{3}, \ldots, x_{n}$, the MK test statistic $\left(U f_{k}\right)$ is given by Eq. (1).

$$
U f_{k}=\left[s_{k}-E\left(s_{k}\right)\right] / \sqrt{\operatorname{Var}\left(s_{k}\right)} \quad(k=2,3, \cdots, n)
$$

where

$$
\begin{gathered}
s_{k}=\sum_{i=1}^{k} \sum_{j}^{i-1} \alpha_{i j} \\
\alpha_{i j}=\left\{\begin{array}{ll}
1, & x_{i}>x_{j} \\
0, & x_{i}<x_{j}
\end{array} \quad 1 \leq j \leq i\right.
\end{gathered}
$$

When we rearrange the series in an opposite order, the new test statistic is given by Eq. (3).

$$
\left\{\begin{array}{l}
U b_{k}=-U f_{K} \\
K=n+1-k
\end{array} \quad(k=1,2, \cdots, n)\right.
$$

When $U f_{k}=U b_{k}$, in other words, the statistic curves have intersections under the confidence level $\alpha$, where the intersection is the aberrance point. Generally, the confidence level $\alpha$ was set at 0.05 . If the intersection point was under the confidence level $\alpha$, then the critical aberrance point of variation was at that period [11]. Accordingly, the stream flow series between two shift points were affirmed as one stream flow series.

\section{2) The tenant method}

To evaluate the ecological flow of the river in each hydrologic series, the Tenant method was applied. It assumed that some percentage of the average flow was needed to maintain a healthy stream flow environment. According to the observed data, the Tennant method supposed that a flow equal to $10 \%$ of the average annual stream flow provided the minimum required condition for aquatic life, $30 \%$ of the average annual stream flow provided a better condition for fishes, and $60-100 \%$ of annual average stream flow provided an optimum condition to maintain the thriving of the river ecosystem. According to the work of Tennant method ([4], [12]), the grades to evaluate the stream flow were classified (Fig. 3).

\section{3) The monthly guaranteed frequency method}

To calculate the ecological water requirement of the Baihe River, the MGF method was applied. According to the MGF method, in April - September, 75\% stream low must be guaranteed, and during October-next March, 50\% stream flow must be guaranteed. Under the guaranteed frequency in 
each season, $20 \%, 40 \%$ and $60 \%$, were taken respectively as the minimum, proper and perfect ecological flow in each season [13].

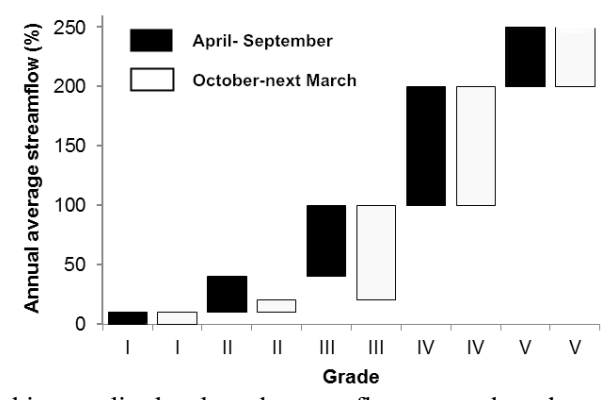

Fig. 3. Habitat quality levels and stream flow ranges based on the Tennant method.

\section{RESULTS AND DISCUSSION}

\section{A. Analysis of Stream Flow Aberrance Points}

The $Z$ values of $U f$ and $U b$ were the statistics of the MK test (Fig. 4). A positive value of $U f$ indicates an increasing trend, and vice versa. The intersection point of $U f$ and $U b$ was under the confident level, so the year 1985 should be affirmed as aberrance year of the streamflow of the Baihe River. According to the MK method, two hydrologic series were distinguished: series 1, the years during 1963-1985 and series 2 , the year during 1986 - 2011. In series 1, the streamflow fluctuated slightly with the $Z$ values of $U f$ curve waved around -1 to 2 . In series 2 , the $Z$ value of $U f$ was always less than -2, which indicated a steady down ward trend of streamflow in the Baihe River. With considering the hydrologic alterations, ecological flow and monthly ecological water requirements would vary.

\section{B. Evaluation of Ecological Flow}

The stream flow frequencies belonging to each level of ecological flow were determined as shown in Table I. Generally the stream flow of the Baihe River was better in other seasons than that in spawning season.

Before 1985, 60.9\% of stream flow was not at the appropriate level during the periods of the spawning season for the Baihe River, which indicated that the ecological environments were not optimistic and the habitat was not appropriate for aquatic life in the spawning season. In other periods, $87.0 \%$ of the stream flow was in appropriate level, which can maintain the basic river ecological system. After $1986,72.4 \%$ of stream flow was not at the appropriate level during the periods of the spawning season for the Baihe River, which illustrated a worse condition than that before the year of 1985. Moreover, in other season, the stream flow decentralized in each grade and only $75.6 \%$ of stream flow was in appropriate level. The comparison in two hydrological series revealed a deteriorated flow regime of the Baihe River.

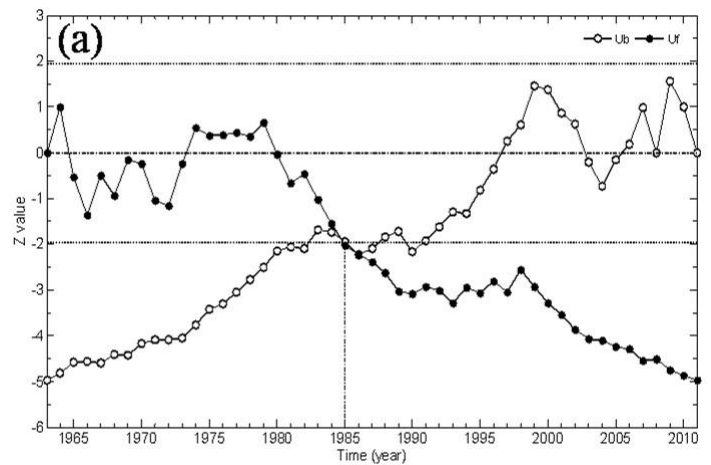

Fig. 4. The stream flow aberrance test with the MK test.

For river ecosystems, if the stream flow is in improper level for a long time, the health of the aquatic ecosystem is threatened. Especially in the spawning season, the low stream flow will be dangerous for the aquatic animal breeding and brood. In an attempt to ensure the fishes' survival and reproduction, the stream flow of the river should be appropriate, especially during the spawning season. To keep the river ecosystem healthy, adaptive measures such as reducing the upstream water intake, maintaining minimum ecological flow in dry season and spawning season by the reservoir operation to fit dynamic development of the water resources system should be taken. The results in this paper provide a basis for making decisions for the ecological protection of the water under hydrological alterations.

TABLE I: PERCENTAge of AVERAge Flow RATE AND THE FREQUENCY DISTRIBUTION BASED ON THE TENANT METHOD

\begin{tabular}{ccccccc}
\hline \hline Series & Months & I (\%) & II (\%) & III (\%) & IV (\%) & V (\%) \\
\hline series 1 & $4-9$ & 0 & 24.6 & 39.1 & 18.9 & 17.4 \\
& $10-3$ & 0 & 5.8 & 87.0 & 7.2 & 0 \\
series 2 & $4-9$ & 0 & 37.8 & 27.6 & 15.4 & 19.2 \\
& $10-3$ & 0.7 & 5.8 & 75.6 & 16 & 1.9 \\
\hline \hline
\end{tabular}

TABLE II: MONTHLy ECOLOGICAL WATER REQUIREMENTS WITH CONSIDERING THE HYDROLOGICAL ALTERATIONS

\begin{tabular}{cccccccccccccc}
\hline \hline \multirow{2}{*}{ Series } & Grade & Jan. & Feb. & Mar. & Apr. & May. & Jun. & Jul & Aug & Sep & Oct. & Nov. & Dec. \\
\hline \multirow{3}{*}{ Series 1 } & Minimum & 1.27 & 1.45 & 1.77 & 1.85 & 0.80 & 1.15 & 5.7 & 13.9 & 3.48 & 2.80 & 2.34 & 1.51 \\
& Proper & 2.54 & 2.91 & 3.54 & 3.71 & 1.60 & 2.30 & 11.3 & 27.9 & 6.96 & 5.60 & 4.68 & 3.03 \\
& Perfect & 3.81 & 4.36 & 5.30 & 5.56 & 2.40 & 3.46 & 17.0 & 41.8 & 10.4 & 8.40 & 7.02 & 4.54 \\
\hline \multirow{3}{*}{ Series 2 } & Minimum & 0.44 & 0.49 & 0.54 & 2.30 & 0.81 & 0.89 & 0.79 & 1.27 & 0.92 & 1.65 & 2.03 & 0.59 \\
& Proper & 0.87 & 0.99 & 1.08 & 4.60 & 1.62 & 1.79 & 1.58 & 2.55 & 1.84 & 3.30 & 4.06 & 1.19 \\
& Perfect & 1.31 & 1.48 & 1.62 & 6.90 & 2.44 & 2.69 & 2.38 & 3.82 & 2.76 & 4.94 & 6.09 & 1.78 \\
\hline \hline
\end{tabular}

\section{Monthly Ecological Water Requirements}

According to the MGF method, three grades of ecological water requirements in each month were calculated in each month with hydrological alterations (Table II). The stream flow concentrated in July to October especially in August, consistent with the wet-season of northern China. Generally, the monthly ecological water requirements in each moth 
(except for April to June) were less after 1986 than that before 1985, which indicated a decreased stream flow trend for the Baihe River. The stream flow from April to June had shown increased trend after the year of 1986, abnormal for the river of northern China, which might the result the climate changes of the northern China. The method will help to give a base for making reasonable reservoir regulation schemes under the hydrological alterations.

\section{CONCLUSIONS}

This research evaluated the ecological flow of the Baihe River with the hydrological alterations. In the research, two hydrological series were distinguished With the MK method, and the ecological flow in each hydrological period was evaluated with the Tennant method. Meanwhile, the monthly ecological water requirements were calculated in spawning and other season with considering the hydrological alterations. The conclusions were drawn as follows.

1) The stream flow during 1963 - 2011 fluctuated in a large scale and generally showed a decreased trend. The MK trend analysis showed that the aberrance year of the streamflow in the Baihe River was the year of 1980s.

2) For the Baihe River, the stream flow regime was in worse condition after 1986 than that before 1985 both in spawning and other seasons.

Based on the analysis of quality of the aquatic ecological environment, there were serious threats to the health of the Baihe River. The ecological stream flow was frequently always in improper condition, which threatened not only the ability of species to live, grow or reproduce but also utilization of water resources. To maintain and restore the ecological conditions of water bodies, human activities must be restricted. With considering the hydrological alterations, the monthly ecological water requirements were calculated. The research will give a basis for resalable water utilization and of the river and dispatching of the reservoir water under stream flow variations.

\section{ACKNOWLEDGMENT}

This research was supported by the Fund for Innovative Research Group of the National Natural Science Foundation of China (No. 51421065).

\section{REFERENCES}

[1] A. Shokoohi and M. Amini, "Introducing a new method to determine rivers' ecological water requirement in comparison with hydrological and hydraulic methods," Int J Environ SciTe., vol. 11, pp. 747-756, 2014.

[2] Z. X. Ye, Y, J. Shen, and Y, P. Chen, "Multiple methods for calculating minimum ecological flux of the desiccated Lower Tarim River, Western China," Ecohydrology., vol. 6, pp. 1040-1047, 2013.

[3] C. Leigh, R. Stubbington, F. Sheldon, and A. J. Boulton, "Hyporheic invertebrates as bioindicators of ecological health in temporary rivers: A meta-analysis," Ecological Indicators, vol. 32, pp. 62-73, 2013

[4] D. L. Tennant, "Instream flow regimens for fish, wildlife, recreation and related environmental resources," Fisheries, vol. 1, pp. 6-10, 1976
[5] A. Shokoohi and M. Amini, "Introducing a new method to determine rivers' ecological water requirement in comparison with hydrological and hydraulic methods," Int J Environ SciTe., vol. 11, pp. 747-756, 2014.

[6] Z. F. Yang and Y. Zhang, "Comparison of methods for ecological and environmental flow in river channels," J Hydrodyn., vol. 18, pp. 294-301, 2003.

[7] Y. D. Chen, Q. Zhang, C. Xu, X. Lu, and S. Zhang. "Multiscale streamflow variations of the Pearl River basin and possible implications for the water resource management within the Pearl River Delta, China," Quatern Int., vol. 226, pp. 44-53, 2010.

[8] Z. X. Bao, J. Y. Zhang, G. P. Wang, G. B. Fu, R. M. He, X. L. Yan, J. L. Jin, Y. L. Liu, and A. J. Zhang, "Attribution for decreasing streamflow of the Haihe River basin, northern China: Climate variability or human activities?" J Hydrol., vol. 460-461, pp. 117-129, 2012.

[9] M. Birsan, L. Zaharia, V. Chendes, and E. Branescu, "Seasonal trends in Romanian streamflow," Hydrol Process., vol. 28, pp. 4496-4505, 2014.

[10] X. Zhai, J. Xia, and Y. Zhang. "Water quality variation in the highly disturbed Huai River Basin, China from 1994 to 2005 by multi-statistical analyses," Sci Total Environ., vol. 496, pp. 594-606, 2014.

[11] F. W. Gerstengarbe and P. C. Werner, "Estimation of the beginning and end of recurrent events within a climate regime," Clim Res., vol. 11, pp. 97-107, 1999.

[12] Z. Ye, Y. Shen, and Y. Chen. "Multiple methods for calculating minimum ecological flux of the desiccated Lower Tarim River, Western China," Ecohydrol, vol. 6, pp. 1040-1047, 2013.

[13] X. Q. Feng, G. X. Zhang, and X. R. Yin, "Calculation of ecological water requirements in the lower reaches of the Taizi River based on ecological protection objectives," Acta Scientiae Circumstantiae., vol, 30, pp. 1466-1471, 2010.

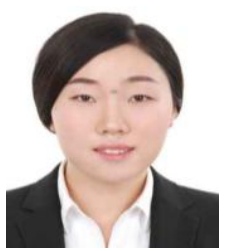

Guangling Hao was born in Jinan City, Shandong province, China on April 17, 1990. She obtained a bachelor degree of environmental science in Shandong Agricultural University in Taian City, China. Now, she is a graduate student majoring in environmental science in School of Environment, Beijing Normal University, Beijing, China.

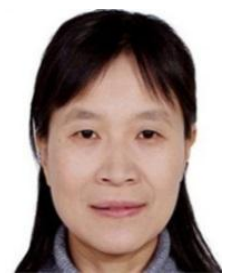

Xuan Wang was born in Lincang, Yunnan province, China. She received her Ph.D degree in Beijing Normal University, China in 2000. She earned her master degree from Sichuan University, China in 1997. Now she is a professor doing research in water resources security assessment and management, water environment simulation, ecological water requirement in School of Environment, Beijing Normal University.

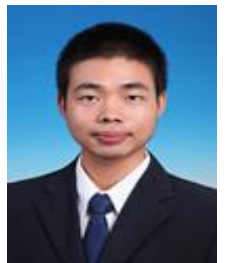

Peiyu Liang was born in Ji'an, Jiangxi province, China. He received his bachelor degree of hydrology and water resources engineering in Wuhan University, Wuhan, China in 2011. He earned his degree of master of hydrology and water resources from Beijing Normal University, Beijing China in 2014. Now, he is working in Zhejiang Institute of Hydraulics and Estuary, China.

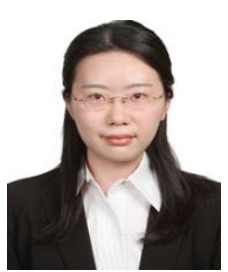

Guannan Cui was born in Tangshan, Hebei province, China. She attended the MIP (master of infrastructure planning) programme in Stuttgart, Germany from 2009 to 2011 and received the master degree. Currently, she is the doctorial candidate in School of Environment, Beijing Normal University, majoring in environmental science. 